\title{
Primary Care Physicians' Personal and Professional Attributes Associated With Forgoing Own Care and Presenteeism: A Cross Sectional Study
}

\author{
Christine Cohidon ${ }^{1 *}$, Liv Mahler $^{2}$, Barbara Broers ${ }^{2}$, Thierry Favrod-Coune ${ }^{2}$, Amir Moussa $^{3}$ \\ and Paul Sebo ${ }^{3}$ \\ ${ }^{1}$ Family Medicine Department, Center for Primary Care and Public Health (Unisanté), University of Lausanne, Lausanne, \\ Switzerland, ${ }^{2}$ Primary Care Division, Geneva University Hospitals, Geneve, Switzerland, ${ }^{3}$ Primary Care Unit, University of Geneva, \\ Geneva, Switzerland
}

\section{OPEN ACCESS}

Edited by:

Thomas Kohlmann, University of Greifswald, Germany

Reviewed by: Armin Gemperli, Swiss Paraplegic Research,

Switzerland Jean-François Chenot, Universitätsmedizin Greifswald,

Germany

*Correspondence: Christine Cohidon christine.cohidon@unisante.ch

Received: 31 August 2021 Accepted: 21 December 2021 Published: 15 February 2022

Citation:

Cohidon C, Mahler L, Broers B, Favrod-Coune T, Moussa A and

Sebo P (2022) Primary Care Physicians' Personal and Professional Attributes Associated With Forgoing Own Care and Presenteeism: A Cross

Sectional Study. Int J Public Health 66:1604442. doi: 10.3389/ijph.2021.1604442
Objective: The aim of this study was to describe the prevalence of forgoing care and forgoing sick leave among primary care physicians (PCPs) in Switzerland and to investigate associated factors.

Methods: A random sample of 1,000 PCPs in French-speaking regions of Switzerland (participation rate: 50\%) was asked whether they had forgone care and sick leave during the last year. Sociodemographic, personal and occupational characteristics were recorded. Logistic regressions were performed to study these behaviours.

Results: $37 \%$ of respondents reported at least one episode of forgoing care and $29 \%$ reported an episode of forgoing sick leave. No associations were found between individual characteristics and forgoing care. A heavy workload was the most common reason evoked for forgoing care. Coming to work when sick (presenteeism) was associated with female sex, younger age, having a chronic illness, working in a suburban area and working full-time.

Conclusion: A high proportion of PCPs in Switzerland is forgoing own care and continues to work despite sickness. New generations of PCPs should require careful monitoring, and specific solutions should be sought to reduce these harmful behaviours.

Keywords: primary care physician, illness behaviour, forgoing care, forgoing sick leave, presenteeism

\section{INTRODUCTION}

According to the "Quintuple aim" defined to guide healthcare organizations in directing their efforts, one part of the healthcare system's mission is ensuring the well-being of its workforce [1,2]. Indeed, sick healthcare professionals negatively affect healthcare systems through lower staff retention, enhanced recruitment needs, lower productivity and efficiency, and ultimately, poorer quality of care and patient safety [3]. Yet, healthcare professionals, especially physicians, seem to be particularly negligent of their own health [4-6]. This behaviour has been described before $[4,7,8]$ and seems to be shared by physicians in the public and private sectors [9]. The literature clearly shows that general practitioners (GPs) tend not to consider themselves as patients [10-12]. 
How physicians neglect their health can be illustrated via several specific behaviours, known as illness behaviours, including forgoing care (defined as not seeking healthcare while presenting medical symptoms) [7, 13], self-treatment $[14,15]$, a reluctance to take sick leave $[3,7]$ and not having their own GP [13]. Forgoing care has mainly been studied in the context of the psychological distress linked to physicians' substantial exposure to occupational stress [16], particularly among GPs $[17,18]$. Yet, physicians' difficulties accepting and dealing with their somatic ailments seem to be compounded when their ailments are psychological, and this could have significant consequences on the quality of care they provide to others [19]. Physical health should not be forgotten either [6]. Regarding self-treatment, Montgomery's literature review reported self-medication rates of over $50 \%$ in three-quarters of the 27 studies analysed [14]. More recently, in a country neighbouring Switzerland, Schulz's study reported a selfmedication rate of $60 \%$ among German GPs [20]. Finally, not only can physicians be reluctant to seek care, they also seem to be hesitant to take sick leave $[4,7,9]$. The prevalence of this behaviour, often termed presenteeism, may be $80-90 \%$ among physicians in comparison with $30-70 \%$ among other professions [9]. Finally, according to the literature, only about $50 \%$ of physicians have their own GP [14], and there are large variations in this rate [13]. Schulz reported that only $19 \%$ of German GPs had their own doctor [20], whereas rates in the general population in Western countries are generally over $75 \%$ in some countries.

GPs' conscious and unconscious opinions and attitudes might help to explain these illness behaviours [21]. GPs may feel uncomfortable in the role of the patient and fear that other colleagues will interpret their need for help as an indicator of their inability to cope [3, 22, 23]. Other reported explanations include workload and lack of time, stigma [19], confidentiality, the fear of being seen as incompetent (by peers or patients) $[10,17,19]$, embarrassment about the triviality of their condition and cultural myths about physicians' invincibility $[6,13,16,17,19,24]$. Finally, financial reasons have also been given by physicians working in private practice [13].

In a context where many Western countries are reporting a shortage of GPs [25], this issue may be particularly critical. Kay's literature review underlined the paucity and poor quality of data about this topic [13]. Schulz et al. mentioned the need to analyse specific reasons for GPs' illness behaviour [20]. Studies on this topic often treat physicians as a homogenous group, paying little attention to potential differences in their sociodemographic/ personal or professional characteristics: existing reviews in this field rarely distinguish between different medical specialities [13, 14, 24]. Preventing GPs' harmful illness behaviours and proposing interventions for change require identifying factors associated with them.

The present study aimed to describe the prevalence of forgoing care and forgoing sick leave in primary care physicians (PCPs) in Switzerland and to investigate sociodemographic, personal health and professional characteristics associated with these illness behaviours.

\section{METHODS}

\section{Study Design and Population}

The present study was based on a large, cross-sectional survey on the health of PCPs (general practitioners, paediatricians and gynaecologists) in French-speaking regions of Switzerland (representing about one third of Switzerland's 8.5 million inhabitants) in autumn 2020. A sample of 1,000 PCPs was randomly drawn from the French-speaking part of the Swiss Medical Association list ( $\mathrm{N}=2,455$ PCPs practicing in this area). This list contains about $95 \%$ of the PCPs in Switzerland. A postal letter invited the selected PCPs to complete the survey via an internet link to an electronic questionnaire. They could also complete a paper version of the paper questionnaire and return it by post. A reminder was sent to non-responders 1 month after the first letter. No incentives were offered for participation. The Regional Research Ethics Committee (CCER) approved this study (Reference 201901850).

\section{Data}

The questionnaire included several parts:

- Sociodemographic characteristics i.e., sex, age group, marital status and nationality;

- Personal health characteristics: perceived health [excellent, very good, good, moderate or poor-for the analyses we included it as continuous variable], having one's own GP [yes, no], having seen one's PCP or a psychiatrist/ psychologist in the past 12 months [yes, no], medical history of main chronic physical and psychological diseases over the five last years and current treatments (see Supplementary Appendix). Regarding illness, we created a three level variable on the existence of a chronic illness, distinguishing between psychological and physical illnesses [yes physical illness/yes psychological illness/no].

- Practice and professional characteristics: medical speciality [general internal medicine, paediatrics, gynaecology], practice size [solo, duo, group practice, other], rural/urban area, number of years worked in private practice, number of half-days worked per week and participation in on-call duty (at the hospital or at the practice) [yes, no]. Urbanity level was defined based on the practice postal code, and then categorized (three levels) according to the typology of municipalities (communes) established by the Swiss Federal Statistical Office (FSO)

- Forgoing care was investigated using the following question: "In the last 12 months, did you ever plan to visit a general practitioner or specialist for a health problem (or a check-up) and then eventually decide not to do so?" [yes, no]. In cases where care had been forgone in the last year, the following answers were available (multiple choices possible): "I was too busy," "I treated the problem by myself," "I did not need a medical consultation in the end," "Other" (to be specified). Forgoing sick leave was investigated using the following question: "In the last 12 months, did you ever consider taking a few days (or more) off work for health reasons 
TABLE 1 | Study population characteristics ( $N=503)$ - [the Swiss Physicians' Health Study, French-speaking Switzerland 2021]

\begin{tabular}{lcc}
\hline Personal characteristics & N & \% or median (IQR) \\
\hline Sex & & \\
$\quad$ Female & 258 & 51.3 \\
Male & 245 & 48.7 \\
Age group & & \\
$\quad$ <45 years old & 139 & 27.6 \\
45-54 years old & 147 & 29.2 \\
55-64 years old & 142 & 28.2 \\
>64 years old & 75 & 14.9 \\
Marital status & & \\
$\quad$ Single & 69 & 13.8 \\
Married & 352 & 70.2 \\
Divorced or separated & 74 & 14.8 \\
Widowed & 6 & 1.2 \\
Nationality & & \\
Swiss & 317 & 63.1 \\
Naturalised Swiss citizen & 117 & 23.3 \\
Other & 68 & 13.5 \\
Existing chronic illness & 248 & 49.4 \\
Perceived health & & \\
Excellent & 90 & 18.0 \\
Very good & 192 & 38.5 \\
Good & 30 & 37.5 \\
Moderate or poor & 237 & 6.0 \\
Have their own doctor & & 47.4 \\
& 90
\end{tabular}

Practice \& professional characteristics

Medical speciality

$\begin{array}{lcc}\text { General internal medicine } & 333 & 66.9 \\ \text { Paediatrics } & 95 & 19.1 \\ \text { Gynaecology } & 70 & 14.0 \\ \text { Type of practice } & & \\ \text { Solo } & 171 & 34.1 \\ \text { Duo } & 105 & 20.9 \\ \text { Group } & 226 & 45.0 \\ \text { Location of practice } & & \\ \text { Urban } & 210 & 41.7 \\ \text { Suburban } & 191 & 38.0 \\ \text { Rural } & 102 & 20.3 \\ \text { Number of years working in private practice } & 487 & 13(16) \\ \text { Number of half-days worked per week } & 500 & 8(2) \\ \text { Participation in on-call duty } & 248 & 49.6\end{array}$

and then eventually give up?" [yes, no]. In cases where sick leave had been forgone in the last year, the following answers were available (multiple choices possible): "I did not want to abandon my patients," "I wanted to avoid financial loss," "I did not need sick leave in the end," "Other" (to be specified).

\section{Statistical Analysis}

First, we carried out descriptive statistics (frequencies). We compared the proportions of forgoing care, forgoing sick leave and reasons for forgoing care and sick leave in subgroups of PCPs, according to gender, age and speciality, using chi-squared tests.

Second, associations between forgoing care or forgoing sick leave (as dependent variables) and PCPs' sociodemographic, personal health and professional characteristics (as independent variables) were estimated using logistic regression models. In a first step, associations with PCPs' sociodemographic, personal health and professional characteristics were assessed using univariate logistic regression models. Variables associated with outcomes (with $p$-values $\leq 0.2$ ) were then included in a multivariate model. Backward stepwise selection was used to obtain the final model that contained all variables with $p$ values $\leq 0.05$, as well as gender and age.

Although we found no associations between forgoing care and any of the independent variables through univariate logistic regressions, we did observe significant differences according to why physicians forwent care; thus, we modelled forgoing care's reasons to study their associations with the independent variables. We created a new variable opposing forgoing care due to a work overload $v$ s. forgoing care for other reasons.

The number of missing data was very small and therefore we did not use the usual techniques recommended for handling missing data, such as mean substitution or imputation. We simply omitted these cases and analyzed the remaining data. All statistical analyses were performed using Stata Software (StataCorp LLC).

\section{RESULTS}

The characteristics of the 503 PCPs (50\% participation rate) who completed the questionnaire are presented in Table 1: $51 \%$ were female, $72 \%$ were $<60$ years old (y.o.), two-thirds were GPs and one-third were paediatricians or gynaecologists.

At least one episode of forgoing care in the previous year was reported by $37 \%$ of PCPs, with no differences regarding sex, age or medical speciality, and $69 \%$ of them stated that this was because of a heavy workload. About half of PCPs reported that they had self-managed their illness (29\%) or that a medical consultation had not been necessary in the end $(21 \%)$. Demographic differences were observed in the reasons why care was forgone: women and younger PCPs were significantly more likely than men and older PCPs, respectively, to report that forgoing care was due to a work overload (79\% women $v s$. $57 \%$ men, $p<0.01$; and $75 \%$ PCPs $<45$ y.o. vs. $23 \%$ PCPs $>64$ y.o, $p<0.01$ global test) (Table 2 ).

Forgoing sick leave in the last year was reported by $29 \%$ of PCPs, with a significantly higher frequency among women $(33 \%$ vs. $25 \%$ in men, $p=0.04$ ) and younger doctors (34\% PCPs $<45$ y.o. vs. $15 \%$ PCPs $>64$ y.o., $p=0.02$ ). The most cited reason for forgoing sick leave was that physicians did not want to abandon their patients $(67 \%)$. This reason was more likely to be reported by women $(75 \%)$ than men $(55 \%, p=0.01)$ and by physicians $<45$ y.o. ( $79 \%$ vs. $50 \%$ PCPs $45-54$ y.o., $p=0.03$ global test). Financial reasons were cited by $53 \%$ of the PCPs, with no differences regarding sex, age or medical speciality. Finally, 54\% of the PCPs thought that they were able to work on regardless (Table 2).

Multivariate analyses showed no associations between forgoing care and personal or professional characteristics. Thus, we also modelled the reasons for forgoing care by opposing a heavy workload (reported at least once) and all other reasons, to study their predictive factors. Forgoing care because of a heavy workload was more frequent among women $(\mathrm{OR}=2.04 ; 95 \%$ CI [0.97-4.29]), among physicians working in 
TABLE 2 | Causes of forgoing care and sick leave according to sex, age and speciality (frequencies) - [the Swiss Physicians' Health Study, French-speaking Switzerland 2021].

\begin{tabular}{|c|c|c|c|c|c|c|c|c|c|c|c|c|c|c|}
\hline & \multirow{2}{*}{$\frac{\mathrm{N}^{\mathrm{a}}}{500}$} & \multirow[t]{2}{*}{ All (\%) } & \multicolumn{2}{|c|}{ Sex (\%) } & \multicolumn{6}{|c|}{ Age (yrs, \%) } & \multicolumn{4}{|c|}{ Speciality $^{\mathrm{b}}(\%)$} \\
\hline & & & Male & Female & $p^{c}$ & $<45$ & $45-54$ & $55-64$ & $>64$ & $p^{c}$ & GIM & Ped & Gyn & $p^{c}$ \\
\hline Forgoing care $^{d}$ & 183 & 36.7 & 35.1 & 38.1 & 0.49 & 38.9 & 39.0 & 38.3 & 24.3 & 0.13 & 37.4 & 30.8 & 42.4 & 0.30 \\
\hline I was too busy & 122 & 68.9 & 57.3 & 78.9 & $<0.01$ & 75.5 & 73.7 & 72.0 & 23.5 & $<0.01$ & 67.2 & 75.0 & 70.4 & 0.71 \\
\hline I treated the problem by myself & 51 & 28.8 & 28.0 & 29.5 & 0.83 & 28.3 & 19.3 & 38.0 & 35.3 & 0.18 & 28.7 & 25.0 & 33.3 & 0.79 \\
\hline I did not need a medical consultation in the end & 38 & 21.5 & 19.5 & 23.2 & 0.56 & 26.4 & 12.3 & 18.0 & 47.1 & 0.01 & 18.0 & 25.0 & 33.3 & 0.19 \\
\hline Forgoing sick leave $e^{e}$ & 145 & 29.1 & 24.8 & 33.1 & 0.04 & 34.5 & 27.4 & 32.6 & 14.9 & 0.02 & 30.6 & 25.5 & 27.3 & 0.60 \\
\hline I did not want to abandon my patients & 97 & 66.9 & 55.0 & 75.3 & 0.01 & 79.2 & 50.0 & 69.6 & 63.4 & 0.03 & 68.9 & 62.5 & 61.1 & 0.71 \\
\hline I wanted to avoid financial loss & 77 & 53.1 & 50.0 & 55.3 & 0.53 & 54.1 & 52.5 & 56.5 & 36.4 & 0.69 & 52.4 & 62.5 & 44.4 & 0.49 \\
\hline I did not need sick leave in the end & 78 & 53.8 & 50.0 & 56.5 & 0.44 & 56.2 & 50.0 & 54.3 & 54.5 & 0.95 & 48.5 & 75.0 & 55.6 & 0.06 \\
\hline
\end{tabular}

${ }^{a}$ Total number of respondents.

${ }^{b}$ GIM: general internal medicine, Ped: paediatrics, Gyn: gynecology.

${ }^{c}$ Chi-squared test.

${ }^{d}$ Other reasons for forgoing care, $N=15$

${ }^{e}$ Other reasons for forgoing sick leave, $N=18$.

TABLE 3|Personal and professional factors associated with PCPs forgoing care due to heavy workloads (vs. forgoing care for other reasons, $\mathrm{N}=183$, logistic regression) [the Swiss Physicians' Health Study, French-speaking Switzerland 2021].

\begin{tabular}{|c|c|c|c|c|c|}
\hline \multirow[t]{2}{*}{ Characteristics } & \multirow[t]{2}{*}{$\mathbf{N}$} & \multirow[t]{2}{*}{$\%^{b}$} & \multirow{2}{*}{$\begin{array}{l}\text { Univariate analyses } \\
\frac{\text { OR }[95 \% \mathrm{Cl}]}{}\end{array}$} & \multicolumn{2}{|c|}{$\begin{array}{l}\text { Multivariate analyses } \\
\text { Final model }^{c}(\mathrm{~N}=176)\end{array}$} \\
\hline & & & & OR $[95 \% \mathrm{Cl}]$ & $p$-value \\
\hline Sex - Ref. Male & 82 & 57.2 & 1 & 1 & \\
\hline Female & 95 & 78.9 & 2.79 [1.44-5.39] & $2.04[0.97-4.29]$ & 0.06 \\
\hline Age - Ref. $<45$ years old & 53 & 75.5 & 1 & 1 & \\
\hline $45-54$ & 57 & 73.7 & 0.91 [0.38-2.15] & $1.03[0.42-2.58]$ & 0.94 \\
\hline $55-64$ & 50 & 72.0 & $0.84[0.35-2.01]$ & $1.22[0.47-3.16]$ & 0.67 \\
\hline$\geq 65$ years old & 17 & 23.5 & 0.10 [0.03-0.36] & $0.15[0.04-0.64]$ & 0.36 \\
\hline Marital status - Ref. married & 132 & 65.9 & 1 & & \\
\hline Single & 20 & 75.0 & $1.55[0.53-4.54]$ & & \\
\hline Divorced & 24 & 79.2 & $1.96[0.69-5.61]$ & & \\
\hline Nationality - Ref. Swiss & 108 & 64.8 & 1 & & \\
\hline Naturalised Swiss citizen & 45 & 73.3 & 1.49 [0.69-3.22] & & \\
\hline Other & 24 & 79.2 & $2.06[0.71-15.96]$ & & \\
\hline Perceived health - (Excellent to poor $)^{a}$ & 176 & - & $1.41[0.93-2.13]$ & & \\
\hline Existing chronic disease - Ref. No & 70 & 72.9 & 1 & & \\
\hline Yes, physical illness & 51 & 56.9 & 0.49 [0.23-1.05] & & \\
\hline Yes, psychological illness & 56 & 75.0 & 1.12 [0.50-2.49] & & \\
\hline Have their own doctor - Ref. No & 93 & 60.2 & 1 & 1 & \\
\hline Yes & 83 & 79.5 & $2.56[1.31-5.04]$ & $2.47[1.18-5.15]$ & 0.02 \\
\hline Setting - Ref. urban & 66 & 60.6 & 1 & 1 & \\
\hline Suburb area & 72 & 79.2 & $2.47[1.16-5.25]$ & $2.47[1.07-5.71]$ & 0.03 \\
\hline Rural area & 39 & 64.1 & $1.16[0.51-2.63]$ & $1.07[0.40-2.41]$ & 0.97 \\
\hline Speciality - Ref. General internal medicine & 122 & 67.2 & 1 & & \\
\hline Paediatrics & 28 & 75.0 & $1.46[0.57-3.73]$ & & \\
\hline Gynaecology & 27 & 70.4 & $1.16[0.47-2.87]$ & & \\
\hline Practice type - Ref. Solo & 47 & 59.6 & 1 & & \\
\hline Duo & 39 & 79.5 & 2.63 [0.99-6.95] & & \\
\hline Group (>2 PCPs) & 81 & 71.6 & $1.71[0.80-3.65]$ & & \\
\hline Participation in on-call duty - Ref No & 87 & 66.7 & 1 & & \\
\hline Yes & 90 & 71.1 & 1.23 [0.65-2.33] & & \\
\hline Number of half-days worked per week ${ }^{a}$ & 177 & & $1.05[0.91-1.21]$ & & \\
\hline Seniority (in years) ${ }^{a}$ & 177 & & 0.97 [0.93-0.99] & & \\
\hline
\end{tabular}

alncluded as a continuous variable, perceived health included 5 levels, from excellent $=1$ to very bad $=5$.

${ }^{b_{\%}}$ forgoing care due to heavy workload.

${ }^{c}$ Hosmer Lemeshow test, $\mathrm{p}=0.83$.

suburbs $(\mathrm{OR}=2.47$ [1.07-5.71] $)$ and those with their own doctor $(\mathrm{OR}=2.47$ [1.18-5.15]), and it was lower among older PCPs (OR $=0.15[0.04-0.64]$ in PCPs $\geq 65$ y.o.) (Table 3). Results were quite similar regarding forgoing sick leave. According to our multivariate analyses, this behaviour was more frequent among women $(\mathrm{OR}=1.71[1.04-2.81])$, physicians who had 
TABLE 4 | Personal and professional factors associated with forgoing sick leave ( $N=503$, logistic regression) - [the Swiss Physicians' Health Study, French-speaking Switzerland 2021].

\begin{tabular}{|c|c|c|c|c|c|}
\hline \multirow[t]{2}{*}{ Characteristics } & \multirow[t]{2}{*}{$\mathbf{N}$} & \multirow[t]{2}{*}{$\%^{b}$} & \multirow{2}{*}{$\begin{array}{l}\text { Univariate analyses } \\
\text { OR }[95 \% \mathrm{Cl}]\end{array}$} & \multicolumn{2}{|c|}{$\begin{array}{l}\text { Multivariate analyses } \\
\text { Final model }^{c}(N=484)\end{array}$} \\
\hline & & & & OR $[95 \% \mathrm{Cl}]$ & $p$-value \\
\hline Sex - Ref. Male & 242 & 24.8 & 1 & 1 & \\
\hline Female & 257 & 33.1 & $1.50[1.01-2.52]$ & 1.59 [0.97-2.63] & 0.07 \\
\hline Age - Ref. <45 years old & 139 & 34.5 & 1 & 1 & \\
\hline $45-54$ & 146 & 27.4 & $0.72[0.43-1.18]$ & $0.64[0.35-1.14]$ & 0.13 \\
\hline $55-64$ & 141 & 32.6 & $0.92[0.56-1.51]$ & 1.07 [0.58-1.97] & 0.82 \\
\hline$\geq 65$ years old & 74 & 14.9 & $0.33[0.16-0.69]$ & $0.50[0.21-1.19]$ & 0.12 \\
\hline Marital status - Ref. Married & 69 & 30.4 & 1 & & \\
\hline Single & 350 & 27.1 & 1.17 [0.67-2.06] & & \\
\hline Divorced & 73 & 32.9 & $1.31[0.76-2.26]$ & & \\
\hline Nationality - Ref. Swiss & 315 & 24.8 & 1 & 1 & \\
\hline Naturalised Swiss citizen & 117 & 36.7 & 1.77 [1.12-2.78] & 1.99 [1.17-3.37] & 0.01 \\
\hline Other & 68 & 35.3 & $1.66[0.95-2.90]$ & $1.53[0.80-2.92]$ & 0.19 \\
\hline Perceived health - (Excellent to poor $)^{a}$ & 498 & & $3.09[2.31-4.13]$ & $2.50[1.81-3.40]$ & 0.01 \\
\hline Existing chronic disease - Ref No & 253 & 19.8 & 1 & 1 & \\
\hline Yes, physical illness & 144 & 23.8 & $1.27[0.77-2.07]$ & $1.33[0.75-2.34]$ & 0.33 \\
\hline Yes, psychological illness & 104 & 58.6 & $5.76[3.50-9.48]$ & $3.79[2.16-6.67]$ & 0.01 \\
\hline Have their own doctor- Ref No & 263 & 25.2 & 1 & - & \\
\hline Yes & 237 & 33.3 & 1.48 [1.01-2.19] & & \\
\hline Setting - Ref. Urban & 208 & 27.4 & 1 & & \\
\hline Suburban area & 190 & 27.9 & $1.02[0.66-1.59]$ & & \\
\hline Rural area & 102 & 34.3 & $1.38[0.83-2.30]$ & & \\
\hline Speciality - Ref. General internal medicine & 337 & 30.6 & 1 & & \\
\hline Paediatrics & 94 & 25.5 & $0.78[0.46-1.31]$ & & \\
\hline Gynaecology & 66 & 27.3 & $0.85[0.47-1.54]$ & & \\
\hline Practice type - Ref. Solo & 165 & 27.3 & 1 & & \\
\hline Duo & 105 & 25.7 & $0.92[0.53-1.61]$ & & \\
\hline Group (>2 PCPs) & 200 & 32.5 & $1.28[0.82-2.01]$ & & \\
\hline Participation in on-call duty -Ref No & 251 & 27.0 & 1 & & \\
\hline Yes & 248 & 31.0 & $1.21[0.82-1.78]$ & & \\
\hline Number of half-days worked per week ${ }^{a}$ & 499 & & $1.10[1.06-1.20]$ & $1.13[1.01-1.26]$ & 0.04 \\
\hline Seniority (in years) ${ }^{a}$ & 480 & & $0.98[0.94-1.00]$ & & \\
\hline
\end{tabular}

alncluded as a continuous variable, perceived health included 5 levels, from excellent $=1$ to very bad $=5$.

${ }^{b_{\%}}$ forgoing sick leave.

${ }^{c}$ Hosmer Lemeshow test, $\mathrm{p}=0.46$.

been naturalised as Swiss citizens $(\mathrm{OR}=1.86[1.10-3.12])$ and physicians with chronic diseases $(\mathrm{OR}=2.21[1.38-3.53])$, and it increased as physicians perceived their health to be poorer $(\mathrm{OR}=$ $2.73[2.01-3.71])$. The probability of forgoing sick leave also increased with the number of half-days worked weekly $(\mathrm{OR}=$ 1.14 [1.02-1.27]). In contrast, forgoing sick leave was less frequent among older PCPs $(\mathrm{OR}=0.41[0.17-0.95]$ in $\mathrm{PCP}$ $\geq 65$ y.o.) (Table 4 ).

\section{DISCUSSION}

One third of the PCPs participating in our study had forgone care in the last year-a very significant proportion. The main reason reported for this illness behaviour was a high workload. Furthermore, about one third also adopted the illness behaviour of presenteeism, mainly because they did not want to abandon their patients, but financial reasons were also mentioned. Forgoing care because of a heavy workload (as opposed to all other causes) and forgoing sick leave were more common among those with certain demographic characteristics, particularly being a woman or a young PCP. Having one's own GP was also associated with a higher frequency of forgoing care because of a heavy workload (as opposed to all other causes).

Our results were consistent with previous studies in terms of the scale of these problematic health behaviours among PCPs [13, 14]. Kay made a literature review of the barriers to seeking healthcare and categorised them into the "patient category" (including embarrassment, fear and time), the "provider category" (including confidentiality and quality of care) and the "system category" (including cultural and structural features) [13]. Our study revealed that a heavy workload was the commonest reason for forgoing care. A heavy workload and a lack of time also frequently appear in the literature but perhaps less often than the discomfort of being a patient [13]. However, our respondents had to choose from a predefined list of three reasons, which partly conditioned their response. They were free to propose another reason, if they wished, but only $9 \%$ did so $(n=$ $15)$. Among the other reasons mentioned, only two GPs reported feelings of embarrassment. Finally, respondents making up excuses cannot be excluded. It may be easier or more selfgratifying for PCPs to report excess work than to acknowledge 
their fears or discomfort, even though the survey ensured their anonymity.

We observed no association between forgoing care and having one's own GP. However, the heavy workload reason for forgoing care (vs. all other reasons) was linked to having a GP. PCPs without a GP responded more often with either "I did not need a medical consultation in the end" or "I treated the problem by myself" as their justification for forgoing care. This result suggests that these PCPs may be in denial of their illness or situation. It also reinforces international recommendations, particularly those of the British Medical Association [26, 27], about the importance of PCPs having their own GP. Less than half of the PCPs in our study had their own GP (47\%). Montgomery's literature review and meta-analysis, which confirmed the previous review by Kay [13], found a mean rate of PCPs with their own GP of 56\%, ranging from 21 to $96 \%$, depending on the study [14]; the lowest rate was in Switzerland [15]. In Schulz's more recent study in Germany, $19 \%$ of GPs were registered as patients [20]. The characteristics of national healthcare systems, such as the existence of gatekeeping systems where patient registration with a GP is compulsory, can obviously affect this rate. However, because PCPs' consultations are often informal, "corridor" consultations $[13,28]$, and because GPs often register with relatives [13], the exact effects of healthcare system characteristics remain unclear. In other words, mandatory registration with a GP will never be a complete solution to the problem of physicians' illness behaviour.

Regarding forgoing sick leave, some research has been conducted on the specific domain of seeking treatment for psychological distress $[17,18,29,30]$. In this context, the embarrassment or discomfort of being a psychologist's patient or the fear of the opinions of colleagues and patients were particularly highlighted. Our results also point in this direction, showing that forgoing sick leave is more frequent in cases of psychological illness. The primary reason reported in our study was that PCPs did not want to abandon their patients. This is characteristic of PCPs' professional dedication. However, financial reasons were also reported in half of the cases. This could also explain the associations observed with PCPs' age. In a private primary care system like Switzerland's, young PCPs may be more worried about financial aspects than their more experienced colleagues. However, the evolution of primary care's organisation in many Western countries, including Switzerland, is towards more group practices and salaried GPs, and this might contribute to reducing the prevalence of this argument in the future [31].

Most of the factors associated with PCPs' illness behaviours were sociodemographic characteristics and personal health attributes. Little association with professional characteristics was observed. However, items on those characteristics were limited in the questionnaire. It should be noted, nevertheless, that the number of half-days worked per week was positively associated with the frequency of forgoing sick leave. A kind of downward spiral of illness behaviour could result from this, with the doctors who work the most being those most at risk of exhaustion and also those who most neglect their health.
The results regarding age were not surprising-perhaps even reassuring-since older GPs are theoretically more vulnerable to illness. However, the results regarding sex were alarming. It should be noted that this result does not necessarily imply an absence of health follow-up among women, nor does it mean that women are more likely to forgo care than men (the difference was non-significant). It does mean that overwork was more frequently given as the reason why women forwent care. However, presenteeism was clearly associated with female sex, as Gustafsson Senden's study also pointed out [32]. Davidson also reported sex differences in opinions and attitudes regarding illness behaviour: women physicians were more likely than men to report that finding a doctor was difficult [12]. The medical profession's increasing feminisation and the often greater overall burden on women (in their private and professional lives) [33] raises fears that the negative impacts of these illness behaviours will increase over time.

Some authors have suggested the creation of a specific branch of healthcare delivery for physicians [19]. This might be an interesting response to illness behaviours surrounding confidentiality or embarrassment. However, it would probably not be sufficient. The valued and respected position of doctors in most societies probably helps to maintain the feelings of invincibility some of them experience (Kay's "cultural barriers" [13]). The ongoing changes in patients' attitudes towards the medical profession and doctors' positions in society could also influence how physicians see themselves. In addition, work's place and image in society are also changing, towards different ways of life and a better work-life balance. This phenomenon is also affecting highly dedicated professionals such as physicians [34]. Finally, the risks of engaging in these illness behaviours should probably be addressed during early medical training and then throughout careers, and on this last point, peer involvement and understanding would surely be valuable. According to Balme, "Doctors need to be supported, not trained in resilience" [35].

\section{Strengths and Limitations}

Despite a good participation rate and good representativity in terms of age and medical specialities, we cannot exclude a selection bias. We were able to compare non-respondents with respondents in terms of sex and age and no differences were found. However, it was not possible to estimate a possible selection biais according to PCPs' health status and interests in their own health. This could have led to an underestimation of the reported frequencies. In addition, our survey was done end of 2020, a year marked by the COVID-19 epidemic and particular strain on the health system. This might have impacted the prevalence rates of presenteeism and forgoing care. Still, we consider that this does not impact our conclusions. The reasons for forgoing care and sick leave were set, limiting participants' possible responses. A qualitative approach would have been more appropriate to explore this issue further. In addition, providing a more in-depth analysis of how professional factors influence illness behaviours would have required information on more variables. However, this was not the survey's specific topic. Another potential limitation is 
in the number of statistical tests which have been carried out and which may have led to too narrow $p$-values. However, when comparing the single-variable models to the selected multivariable models, the main findings are quite similar which tends to show the robustness of our findings. Finally, because the study was cross-sectional, no causal conclusions can be drawn. One of the study's strengths was that it focussed on PCPs, which, to the best of our knowledge, has never been done. Despite the fact that the study was conducted in Switzerland, we believe the results are probably generalisable to a large number of countries with comparable primary care systems, particularly European countries like France or Germany. Although there is some literature on barriers to healthcare access and doctors' presenteeism [13], studies on the personal health determinants of such behaviours are scarce. Our study showed that female and young PCPs, in addition to those with chronic diseases, may be particularly prone to adopting harmful illness behaviours, especially presenteeism. Those working full-time were also more at risk. These results could be significant in helping to improve the effectiveness of preventive health interventions targeting this population.

\section{Conclusion}

While it is important to have doctors who are highly dedicated to their work, healthcare systems must also ensure their sustainability and provide good quality care to patients. As part of this aim, the health and illness behaviours of primary care physicians are key issues. The evolution of primary care's organisation combined with physicians' gradually changing expectations of their work-life balance may have a positive impact on their future illness behaviours. Nevertheless, new generations of doctors-particularly young, female PCPs-seem reluctant to accord enough importance to their own health. They deserve careful monitoring, and specific solutions should be sought to reduce their tendencies to forgo care and sick leave.

\section{KEY POINTS}

- 37 and 29\% of PCPs in French-speaking Switzerland reported at least one episode of forgoing care or sick leave, respectively;

- Presenteeism was more associated with female sex, younger age, having a chronic psychological illness, working in a suburb and working full-time;

\section{REFERENCES}

1. Bodenheimer T, Sinsky C. From Triple to Quadruple Aim: Care of the Patient Requires Care of the Provider. Ann Fam Med (2014) 12(6):573-6. doi:10.1370/ afm.1713

2. Epperson WJ, Childs SF, Wilhoit G. Provider Burnout and Patient Engagement: The Quadruple and Quintuple Aims. J Med Pract Manage (2016) 31(6):359-63.

3. Wallace JE, Lemaire JB, Ghali WA. Physician Wellness: a Missing Quality Indicator. The Lancet (2009) 374(9702):1714-21. doi:10.1016/s0140-6736(09) 61424-0
- No associations between personal health characteristics and forgoing care were observed, but differences did exist between the reasons given for forgoing care.

\section{ETHICS STATEMENT}

The studies involving human participants were reviewed and approved by Regional Research Ethics Committee (CCER) (Reference 2019-01850). Written informed consent for participation was not required for this study in accordance with the national legislation and the institutional requirements.

\section{AUTHOR CONTRIBUTIONS}

$\mathrm{BB}, \mathrm{TF}-\mathrm{C}$, and PS are the global survey's principal investigators. In addition, $\mathrm{CC}$ and $\mathrm{LM}$ contributed to the global protocol. LM was responsible of the implementation of the survey. AM managed the collected data. CC designed the analysis plan for the present study. CC performed the analyses and wrote the first draft of the present article. All authors read, provided feedback and approved the final version of the manuscript.

\section{FUNDING}

The authors declare that this study received funding from the Faculty of medicine, University of Geneva. The funder was not involved in the study design, collection, analysis, interpretation of data, the writing of this article or the decision to submit it for publication.

\section{CONFLICT OF INTEREST}

The authors declare that the research was conducted in the absence of any commercial or financial relationships that could be construed as a potential conflict of interest.

\section{SUPPLEMENTARY MATERIAL}

The Supplementary Material for this article can be found online at: https://www.ssph-journal.org/articles/10.3389/ijph.2021.1604442/ full\#supplementary-material

4. McKevitt C, Morgan M. Illness Doesn't Belong to Us. J R Soc Med (1997) 90(9): 491-5. doi:10.1177/014107689709000907

5. Wessley A GC. When Doctors Need Treatment: an Anthropological Approach to Why Doctors Make Bad Patients (2013). Available at: http://careers.bmj. com/careers/advice/view-article. html?id=20015402. (Accessed January 4, 2022).

6. Kay MP, Mitchell GK, Del Mar CB. Doctors Do Not Adequately Look after Their Own Physical Health. Med J Aust (2004) 181(7):368-70. doi:10.5694/ j.1326-5377.2004.tb06329.x

7. Baldwin PJ, Dodd M, Wrate RM. Young Doctors' Health-II. Health and Health Behaviour. Soc Sci Med (1997) 45(1):41-4. doi:10.1016/s0277-9536(96)00307-3 
8. Dowling HF. Physician Heal Thyself. Gp (1955) 11(1):69-73.

9. Gustafsson S, Løvseth L, Schenck-Gustafsson K, Fridner A. What Makes Physicians Go to Work while Sick: a Comparative Study of Sickness Presenteeism in Four European Countries (HOUPE). Swiss Med Wkly (2013) 143:w13840. doi:10.4414/smw.2013.13840

10. Thompson WT, Cupples ME, Sibbett CH, Skan DI, Bradley T. Challenge of Culture, Conscience, and Contract to General Practitioners' Care of Their Own Health: Qualitative Study. Bmj (2001) 323(7315):728-31. doi:10.1136/ bmj.323.7315.728

11. Nielsen BM. I Am a Doctor, So I Am in Control. Ugeskr Laeger (2002) 164(45): 5235-9.

12. Davidson SK, Schattner PL. Doctors' Health-seeking Behaviour: a Questionnaire Survey. Med J Aust (2003) 179(6):302-5. doi:10.5694/j.13265377.2003.tb05552.x

13. Kay M, Mitchell G, Clavarino A, Doust J. Doctors as Patients: a Systematic Review of Doctors' Health Access and the Barriers They Experience. Br J Gen Pract (2008) 58(552):501-8. doi:10.3399/bjgp08x319486

14. Montgomery AJ, Bradley C, Rochfort A, Panagopoulou E. A Review of SelfMedication in Physicians and Medical Students. Occup Med (2011) 61(7): 490-7. doi:10.1093/occmed/kqr098

15. Schneider M, Bouvier Gallacchi M, Goehring C, Künzi B, Bovier PA. Personal Use of Medical Care and Drugs Among Swiss Primary Care Physicians. Swiss Med Wkly (2007) 137(7-8):121-6.

16. Clough BA, March S, Leane S, Ireland MJ. What Prevents Doctors from Seeking Help for Stress and Burnout? A Mixed-Methods Investigation Among Metropolitan and Regional-Based Australian Doctors. J Clin Psychol (2019) 75(3):418-32. doi:10.1002/jclp.22707

17. Spiers J, Buszewicz M, Chew-Graham CA, Gerada C, Kessler D, Leggett N, et al. Barriers, Facilitators, and Survival Strategies for GPs Seeking Treatment for Distress: a Qualitative Study. Br J Gen Pract (2017) 67(663):e700. doi:10.3399/bjgp17x692573

18. Spiers J, Buszewicz M, Chew-Graham C, Gerada C, Kessler D, Leggett N, et al. Who Cares for the Clinicians? the Mental Health Crisis in the GP Workforce. Br J Gen Pract (2016) 66(648):344-5. doi:10.3399/bjgp16x685765

19. Garelick AI. Doctors' Health: Stigma and the Professional Discomfort in Seeking Help. Psychiatrist (2012) 36:81-4. doi:10.1192/pb.bp.111.037903

20. Schulz S, Einsle F, Schneider N, Wensing M, Gensichen J. Illness Behaviour of General Practitioners-A Cross-Sectional Survey. Occmed (2017) 67(1):33-7. doi:10.1093/occmed/kqw135

21. Uallachain GN. Attitudes towards Self-Health Care: a Survey of GP Trainees. Ir Med J (2007) 100(6):489-91.

22. Roberts LW, Warner TD, Rogers M, Horwitz R, Redgrave G. Medical Student Illness and Impairment: a Vignette-Based Survey Study Involving 955 Students at 9 Medical Schools. Compr Psychiatry (2005) 46(3):229-37. doi:10.1016/ j.comppsych.2004.08.008

23. Roberts LW, Warner TD, Smithpeter M, Rogers M, Horwitz R. Medical Students as Patients: Implications of Their Dual Role as Explored in a Vignette-Based Survey Study of 1027 Medical Students at Nine Medical Schools. Compr Psychiatry (2011) 52(4):405-12. doi:10.1016/j.comppsych.2010.09.004
24. Morishita M, Iida J, Nishigori H. Doctors' Experience of Becoming Patients and its Influence on Their Medical Practice: A Literature Review. Explore (2020) 16(3):145-51. doi:10.1016/j.explore.2019.10.007

25. Shen X, Jiang H, Xu H, Ye J, Lv C, Lu Z, et al. The Global Prevalence of Turnover Intention Among General Practitioners: a Systematic Review and Meta-Analysis. BMC Fam Pract (2020) 21(1):246. doi:10.1186/s12875-02001309-4

26. British Medical Association. Ethical Responsibilities in Treating Doctors Who Are Patients. Guidance from the Ethics Department (1995). Available at: http:// www.bma.org.uk/images/Doctor\%20patients\%20new\%20layout\%202_tcm41147309.pdf (Accessed October, 2008).

27. Fox FE, Taylor GJ, Harris MF, Rodham KJ, Sutton J, Scott J, et al. "It's Crucial They're Treated as Patients": Ethical Guidance and Empirical Evidence Regarding Treating Doctor-Patients. J Med Ethics (2010) 36(1):7-11. doi:10.1136/jme.2008.029066

28. Domeyer-Klenske A, Rosenbaum M. When Doctor Becomes Patient: Challenges and Strategies in Caring for Physician-Patients. Fam Med (2012) 44(7):471-7.

29. Stanton J, Randal P. Doctors Accessing Mental-Health Services: an Exploratory Study. BMJ Open (2011) 1(1):e000017. doi:10.1136/bmjopen2010-000017

30. Stanton J, Randal P. Developing a Psychiatrist-Patient Relationship when Both People Are Doctors: a Qualitative Study. BMJ Open (2016) 6(5):e010216. doi:10.1136/bmjopen-2015-010216

31. Cohidon C, Cornuz J, Senn N. Primary Care in Switzerland: Evolution of Physicians' Profile and Activities in Twenty Years (1993-2012). BMC Fam Pract (2015) 16:107. doi:10.1186/s12875-015-0321-y

32. Gustafsson Sendén M, Schenck-Gustafsson K, Fridner A. Gender Differences in Reasons for Sickness Presenteeism - a Study Among GPs in a Swedish Health Care Organization. Ann Occup Environ Med (2016) 28:50. doi:10.1186/ s40557-016-0136-x

33. Tawfik DS, Shanafelt TD, Dyrbye LN, Sinsky CA, West CP, Davis AS, et al. Personal and Professional Factors Associated with Work-Life Integration Among US Physicians. JAMA Netw Open (2021) 4(5):e2111575. doi:10.1001/jamanetworkopen.2021.11575

34. Kinouani S, Boukhors G, Luaces B, Durieux W, Cadwallader J-S, Aubin-Auger I, et al. Private or Salaried Practice: How Do Young General Practitioners Make Their Career Choice? A Qualitative Study. BMC Med Educ (2016) 16(1):231. doi:10.1186/s12909-016-0754-6

35. Balme E, Gerada C, Page L. Doctors Need to Be Supported, Not Trained in Resilience. BMJ (2015) 351:h4709. doi:10.1136/bmj.h4709

Copyright $\odot 2022$ Cohidon, Mahler, Broers, Favrod-Coune, Moussa and Sebo. This is an open-access article distributed under the terms of the Creative Commons Attribution License (CC BY). The use, distribution or reproduction in other forums is permitted, provided the original author(s) and the copyright owner(s) are credited and that the original publication in this journal is cited, in accordance with accepted academic practice. No use, distribution or reproduction is permitted which does not comply with these terms. 